\title{
Attribution of the Recent Winter Sea Ice Decline over the Atlantic Sector of the Arctic Ocean*
}

\author{
DOO-SUN R. PARK \\ Department of Meteorology, The Pennsylvania State University, University Park, Pennsylvania, and Research \\ Institute of Basic Sciences, Seoul National University, Seoul, South Korea \\ SUKYOUNG LEE \\ Department of Meteorology, The Pennsylvania State University, University Park, Pennsylvania, and School \\ of Earth and Environmental Sciences, Seoul National University, Seoul, South Korea \\ STEVEN B. FELDSTEIN \\ Department of Meteorology, The Pennsylvania State University, University Park, Pennsylvania
}

(Manuscript received 13 January 2015, in final form 8 March 2015)

\begin{abstract}
Wintertime Arctic sea ice extent has been declining since the late twentieth century, particularly over the Atlantic sector that encompasses the Barents-Kara Seas and Baffin Bay. This sea ice decline is attributable to various Arctic environmental changes, such as enhanced downward infrared (IR) radiation, preseason sea ice reduction, enhanced inflow of warm Atlantic water into the Arctic Ocean, and sea ice export. However, their relative contributions are uncertain. Utilizing ERA-Interim and satellite-based data, it is shown here that a positive trend of downward IR radiation accounts for nearly half of the sea ice concentration (SIC) decline during the 1979-2011 winter over the Atlantic sector. Furthermore, the study shows that the Arctic downward IR radiation increase is driven by horizontal atmospheric water flux and warm air advection into the Arctic, not by evaporation from the Arctic Ocean. These findings suggest that most of the winter SIC trends can be attributed to changes in the large-scale atmospheric circulations.
\end{abstract}

\section{Introduction}

In recent decades, Arctic sea ice cover has been rapidly shrinking (Serreze et al. 2007; Simmonds 2015), and an ice-free summer Arctic Ocean is expected to appear later this century (Comiso et al. 2008; Wang and Overland 2009, 2012). Most of the previous research on Arctic sea ice focused on the summer season, because winter sea ice cover had shrunk only modestly prior to the steep decline that began in 2005 (Comiso 2006; Francis and Hunter 2007). According to Serreze et al.

\footnotetext{
* Supplemental information related to this paper is available at the Journals Online website: http://dx.doi.org/10.1175/JCLI-D-15-0042.s1.

Corresponding author address: Sukyoung Lee, Department of Meteorology, The Pennsylvania State University, 524 Walker Building, University Park, PA 16802-5013.

E-mail: sxl31@psu.edu
}

(2007), over the past three decades, the overall decline rate of January sea ice extent $\left(-3.1 \%\right.$ decade $\left.^{-1}\right)$ was less than half that for September $\left(-8.6 \%\right.$ decade $\left.^{-1}\right)$. However, summer sea ice is sensitive to the sea ice conditions of the previous winter (Rigor et al. 2002). In fact, correlations in Arctic sea ice area are higher between summer and the preceding winter than between summer and the following winter (Lee 2014; Park et al. 2014, manuscript submitted to J. Climate). Therefore, it is important to investigate winter sea ice processes for understanding sea ice variability and its trend.

There are several mechanisms that can account for the winter sea ice decline. Their relative contributions however are still uncertain. From the perspective that the icealbedo feedback is the main driver behind the surface warming during the cold season, it was suggested that winter sea ice growth is inhibited by surface heat fluxes from ocean water that was heated during the preceding warm season (Lindsay and Zhang 2005; Stroeve et al. 
2012b). In the same vein, it is probable that the spatial pattern of the sea ice concentration (SIC) during the autumn influences the subsequent winter SIC by acting as an initial condition for the winter season. The enhanced inflow of warm Atlantic and Pacific water into the Arctic is also a likely cause of the diminished sea ice (Shimada et al. 2006; Spielhagen et al. 2011). An additional mechanism that can drive the sea ice reduction includes the increased export of sea ice through the Fram Strait (Rigor et al. 2002; Kwok et al. 2009). Last, changes in radiative heating associated with downward infrared (IR) radiation emitted by water vapor and clouds can either melt sea ice or hinder its formation (Francis et al. 2005). Arctic clouds generally warm the surface during most seasons, with this warming effect reaching its maximum during the cold season (Walsh and Chapman 1998; Intrieri et al. 2002).

In this study, we attempt to quantify the contributions by the aforementioned processes and to examine further their causal relationships with winter sea ice variability using reanalysis and satellite data. Although climate models are powerful tools for a process study, the pervasive underestimation of the sea ice decline by the models (Stroeve et al. 2012a) suggests that relevant physical processes are not sufficiently well represented in the models. Therefore, appropriate data analysis can help fill the gaps in our understanding even if observation-based data have their own limitations. The rest of the present study is organized as follows. Section 2 describes the data and methods used. The results of our analyses are presented in section 3 , and the conclusions are provided in section 4 .

\section{Data and methods}

\section{a. Data}

In this study, we used atmospheric and oceanic variables from the ERA-Interim (ERAI) dataset (Dee et al. 2011). These variables include tropospheric temperature, vertically integrated total column water, its horizontal flux, evaporation, surface heat fluxes, sea surface temperature (SST), and SIC. For sea ice motion, data provided by the National Snow and Ice Data Center (NSIDC) were used (Fowler et al. 2013). In addition, for the purpose of crosschecking our results, all of the SIC analyses were also repeated using SIC data from the NSIDC (Cavalieri et al. 1996). Since both SIC datasets are derived from satellite observations, as can be seen by comparing Figs. 1-5 with supplementary Figs. 1-5, they share key features of SIC variability and show good agreement with each other (supplemental information is available online at http://dx. doi.org/10.1175/JCLI-D-15-0042.s1). On the Atlantic side of the Arctic Ocean, there are strong, significant downward SIC trends (up to $-0.24 \% \mathrm{yr}^{-1}$ ), and the spatial

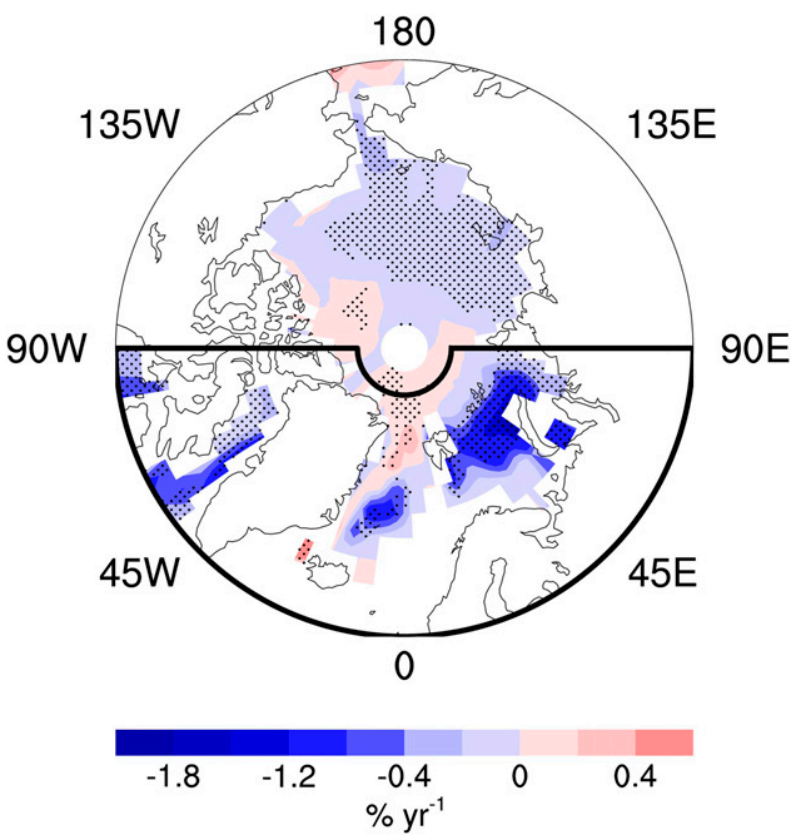

FIG. 1. Linear trend of DJF 1979-2011 mean Arctic SIC. The black thick fan shape represents the Atlantic sector of the Arctic (i.e., from $60^{\circ} \mathrm{N}$ to $85^{\circ} \mathrm{N}$ and from $90^{\circ} \mathrm{W}$ to $90^{\circ} \mathrm{E}$ ). Dots indicate statistical significance at the $90 \%$ confidence level based on a Student's $t$ test.

patterns are similar between the ERAI and NSIDC datasets (cf. Fig. 1 and supplementary Fig. 1). The SIC trends show opposite sign over the Pacific side of the Arctic Ocean, but the trends are weak. Thus, the rest of the analysis will focus on the SIC decline in the Atlantic sector where the SIC trends are significant and consistent between the two datasets. Here, we adopted the ERAI SIC data as the primary dataset because the winter of 1987 is missing in the NSIDC SIC dataset. The NSIDC SIC data used here are regridded data (from $25 \mathrm{~km} \times 25 \mathrm{~km}$ to $1^{\circ} \times 1^{\circ}$ longitude-latitude) provided by Dr. Yu Kosaka at the University of California, San Diego. The sea ice motion data were similarly regridded prior to our analysis.

\section{b. Methods}

We utilized both daily and seasonal mean variables for the boreal winter [December-February (DJF)] of 1979-2011. Prior to all analyses, daily variables were deseasonalized by subtracting smoothed calendar mean values. Seasonal mean values were then calculated by taking a DJF average for each year. For each variable, the resulting time series, composed of 33 values (DJF of 1979/80-2011/12), embodies interannual variability. For SIC, we also used September-November data to represent the autumn SIC.

To utilize the observational data, we took an approach based on the perspective that the long-term SIC trend may be realized through the same processes that cause 
a)

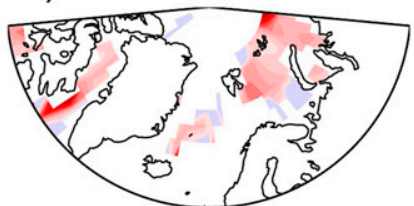

b)

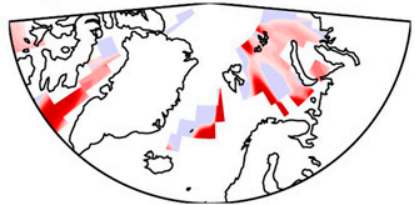

c)

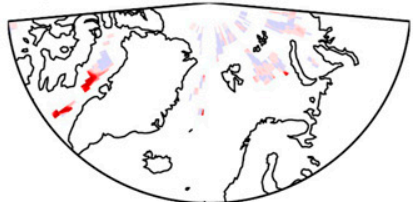

d)

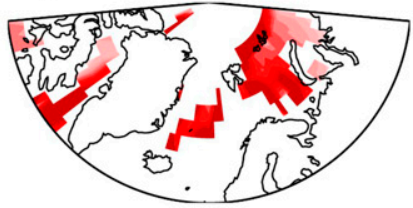

e)

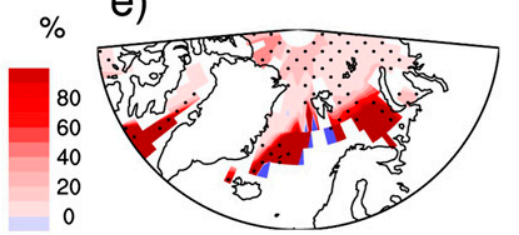

f)

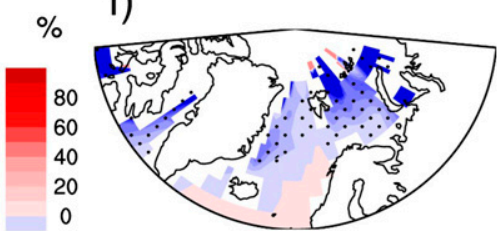

g)

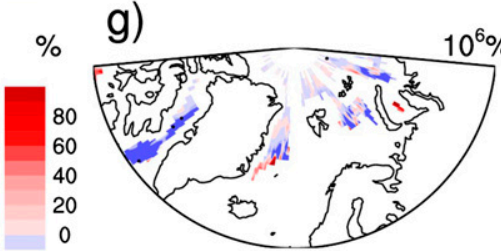

h)

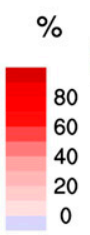

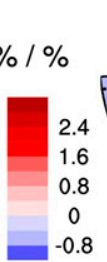

i)

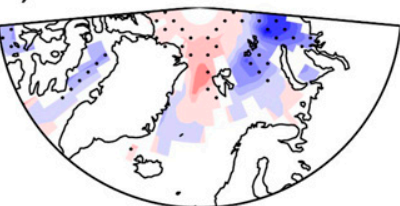

$\% \mathrm{yr}^{-1}$
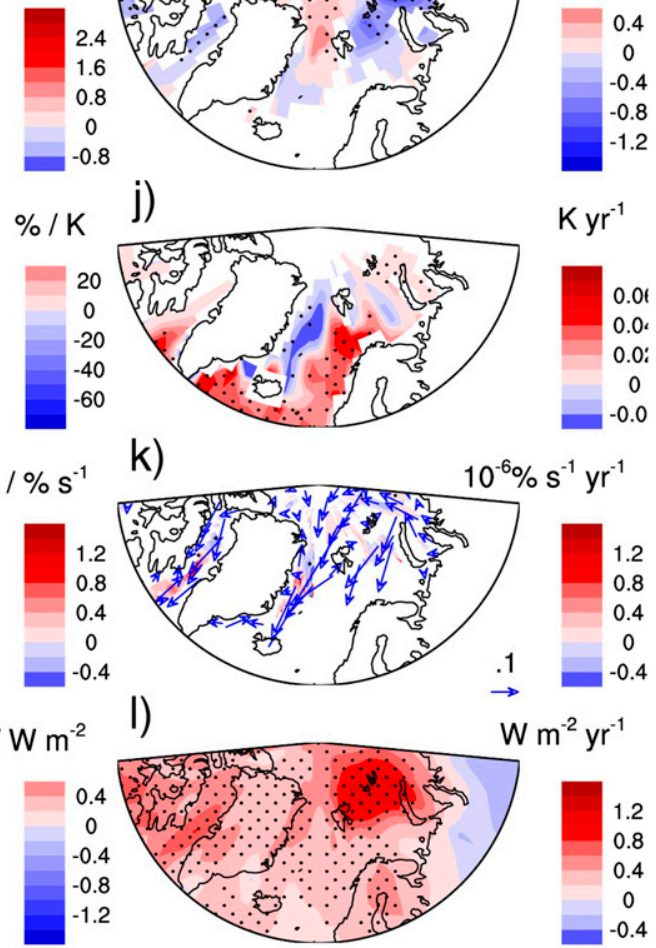

FIG. 2. Contributions to the (a)-(d) sea ice trend, (e)-(h) linear regressions against the winter SIC, and (i)-(l) linear trends of the four variables for autumnal SIC (first row), SST (second row), sea ice convergence and motion (third row), and downward IR radiation (fourth row). Dots and vectors indicate statistical significance at the $90 \%$ confidence level based on a Student's $t$ test.

interannual variability in SIC. A useful analogy is El Niño's influence on rains over California (Schonher and Nicholson 1989): in this case, while the root cause is the slowly evolving anomalies in the tropical Pacific SSTs, their influence on the rains is realized through rapidly evolving weather systems. All of the mechanisms under consideration-Arctic SST, the autumn SIC, sea ice drift, and downward IR radiation-undergo interannual variations. Therefore, we first calculated the interannual relationship between each of these variables and SIC, and then evaluated the extent to which the trend in each of these variables is associated with the SIC trend. As will be described below, prior to calculating the interannual relationship, the seasonal mean values were detrended.

For a concrete description of this approach, we expressed SIC at each data point as a function of the four variables: $f \cong f\left(f_{o}, T, C, R\right)$, where $f$ is the winter SIC, $f_{o}$ is the autumn SIC, $T$ is the SST, $C$ is the sea ice convergence, and $R$ is the downward IR radiation. Then, the 1979-2011 trend in $f$, caused, for example, by the trend in $f_{o}$, can be expressed as $\left(\delta f / \delta f_{o}\right) \Delta f_{o}$, where $\delta f / \delta f_{o}$ is the change in $f$ with respect to change in $f_{o}$ and can be estimated by calculating a linear regression coefficient at each grid point between $f$ and $f_{o}$ using the detrended seasonal mean data; $\Delta f_{o}$ is the 1979-2011 trend in $f_{o}$. The 1979-2011 trend in $f$ caused by the remaining three variables can be similarly calculated.

Once the dominant factor (among the four variables) is identified, we will investigate how this factor influences SIC. For this purpose, we examine the time evolution of the variables under consideration and infer causality through their lead-lag relationship. The time evolution can be examined effectively using a daily projection time series (Feldstein 2002) that measures how closely the SIC anomaly, at any given day, resembles the SIC trend pattern. Although the aforementioned regression analysis is performed using seasonal mean data, we examine daily time series for studying causality because the average $e$-folding time scale of the SIC projection time series is 9 days, much less than the 90 days of DJF. The projection time series $\left(P_{t}\right)$ used here is constructed using the following definition:

$$
P_{t}=\sum_{\lambda} \sum_{\theta} x(\lambda, \theta, t) \dot{x}(\lambda, \theta) \cos ^{1 / 2} \theta,
$$

where $x(\lambda, \theta, t)$ is the variable of interest, for example, SIC, downward IR radiation, at a given day $(t)$, latitude $(\theta)$, and longitude $(\lambda)$; and $\dot{x}(\lambda, \theta)$ is the linear trend 


\section{a) Downward IR \& SIC}

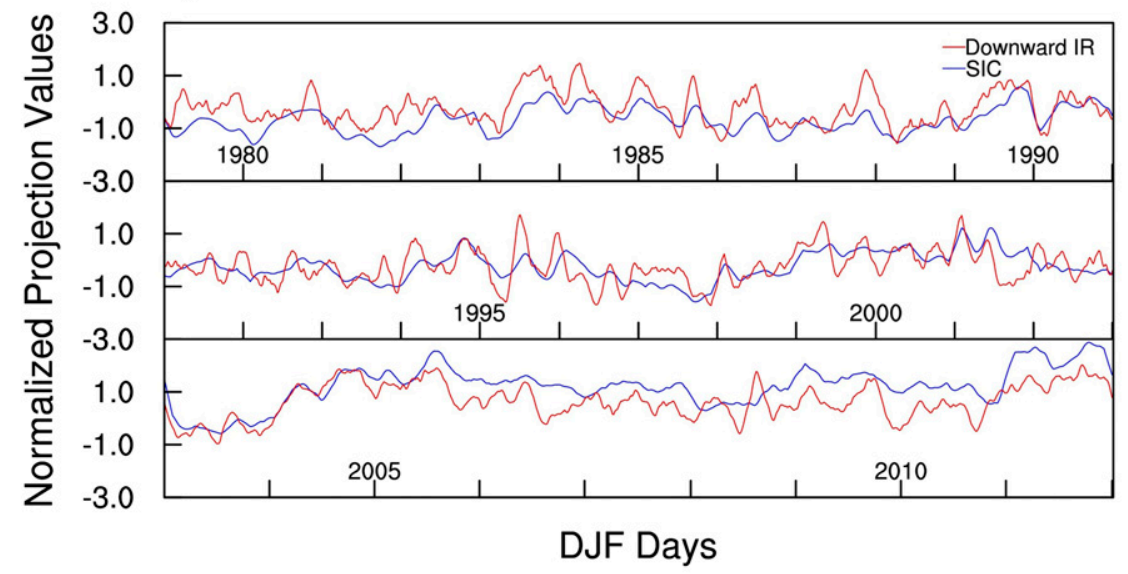

b) Lag correlation

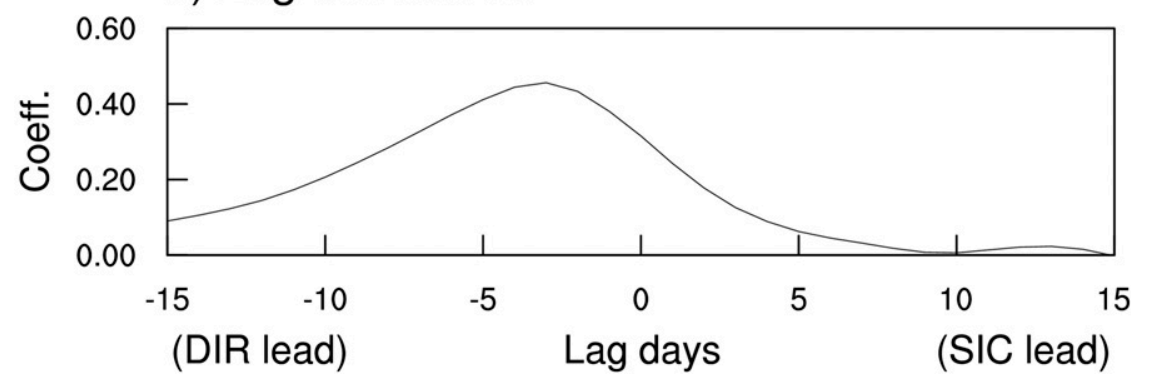

FIG. 3. (a) 15-day running-mean projection time series of downward IR radiation (red solid line) and SIC (blue solid line); every tick mark indicates the end and beginning of each winter.

(b) Lag-day correlations between the downward IR radiation and SIC projection time series.

pattern of the variable. The horizontal extent of $x(\lambda, \theta, t)$ is confined to the region where sea ice has been observed on at least one day for the years 1979-2011 within the Atlantic sector. Prior to constructing lead-lag relationships among each variable's $P_{t}$ (for Figs. 4, 5), interannual variability was removed by subtracting the DJF average for each year. The resulting time series are then normalized by their own $1 \sigma$ values. The lead-lag relationships are constructed by calculating composites of the various projection time series where the lag- 0 days are defined as those days when the SIC projection values first cross a threshold from less than to greater than 1.0 standard deviation. To definitely divide every high SIC projection event, another lag-0 day is not allowed within a relatively short time (i.e., 15 days; note that our results are not sensitive to this threshold day used) from the first lag-0 day defined. The statistical significance of these composites, to be presented in Figs. 4, 5, is determined by using a Monte Carlo method. Arbitrary composites were performed 10000 times with randomly selected projection values. A normal distribution is satisfied with these composites, which are compared to the original selected composite. For the other figures, the Student's $t$ test was performed.

\section{Results}

We found that most of the decline in winter $\operatorname{SIC}(\Delta f)$ is associated with a positive trend in downward IR radiation $(\Delta R)$, that is, $\Delta f \cong(\delta f / \delta R) \Delta R$. This can be seen from the left column of Fig. 2, which displays the ratio of each of the four contributions to each variable-induced $\Delta f$ to the actual $\Delta f:\left(\delta f / \delta f_{o}\right)\left(\Delta f_{o} / \Delta f\right)$, $(\delta f / \delta T)(\Delta T / \Delta f),(\delta f / \delta C)(\Delta C / \Delta f),(\delta f / \delta R)(\Delta R / \Delta f)$. The downward IR radiation contribution (Fig. 2 d) often exceeds $50 \%$, whereas each of the other three contributions explains a notably smaller fraction. The autumn SIC is positively correlated with that of the following winter (Fig. 2e), but its contribution is small (Fig. 2a) in part because of the weak trend in autumn SIC (Fig. 2i). As expected, SST is negatively correlated with SIC (Fig. 2f), and the SST trend (Fig. 2j) is positive except over the Fram Strait. Over Baffin Bay, the SST contribution accounts for a substantial fraction of the SIC trend (Fig. 2b), yet the downward IR radiation contribution is still greater 


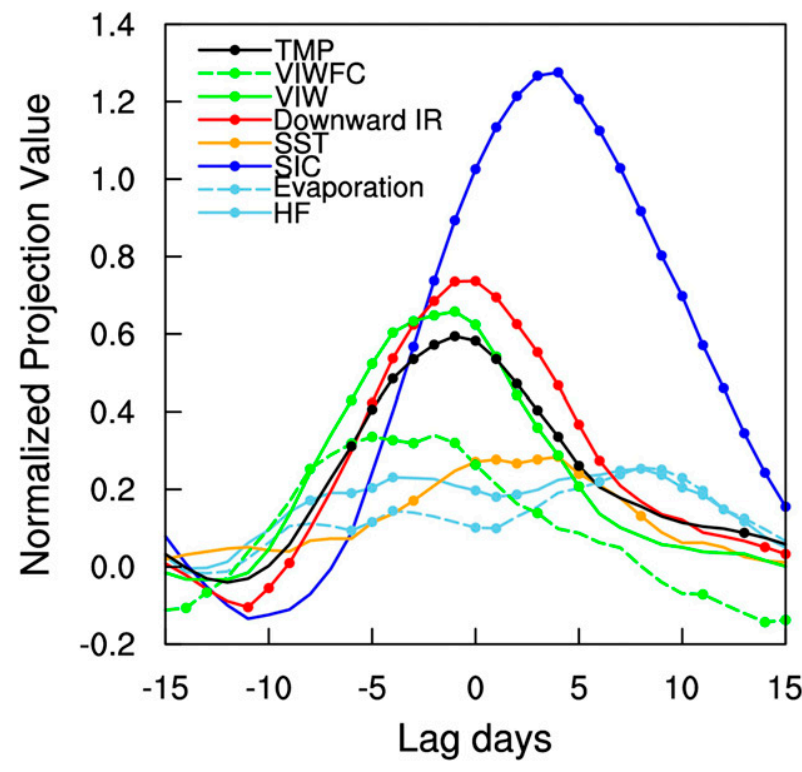

FIG. 4. 10-day running-mean lag-day composites of 1000-400-hPa TMP (black solid), VIWFC (green dashed), VIW (green solid), downward IR radiation (red solid), SST (orange solid), SIC (blue solid), evaporation (sky blue dashed), and upward heat fluxes (HF; sky blue solid) projection time series. Filled dots indicate statistical significance at the $90 \%$ confidence level, evaluated with a Monte Carlo method where the composite values were compared against 10000 randomly selected samples.

(Fig. 2d). Over the Barents-Kara Seas, the SST trend is weak (Fig. 2j) and hence has a negligible effect on the SIC trend (Fig. 2b). The trend in the sea ice motion vectors indicates that sea ice outflow through the Fram Strait had strengthened (Fig. 2k), which is consistent with the earlier finding by Kwok et al. (2009). However, the interannual time-scale regression does not show a statistically significant signal (Fig. 2g); hence, the influence of sea ice convergence (Fig. 2c) appears to be negligible. Finally, the downward IR radiation trend shows a large increase over Baffin Bay and the Greenland-Barents-Kara Seas (Fig. 2l), with its pattern closely matching the SIC trend pattern (cf. Fig. 21 with Fig. 1).

Given the finding that downward IR radiation is the variable most closely associated with the SIC trend and that it accounts for as much as $50 \%$ of the observed trend, we next investigate the causal relationship between the downward IR radiation and the SIC trends. As was described in section 2, we examine the time evolution of the variables using daily projection time series and infer causality through their lead-lag relationship. It is important to examine the causal relationships using daily data because the average $e$-folding time scale of the SIC projection time series is 9 days, and the $e$-folding time scale for the downward IR radiation projection time series is 4 days. Therefore, the seasonal mean values (used for calculating Fig. 2) reflect the interannual variation of the daily fluctuations (Lee and Feldstein 2013; Ballinger and Sheridan 2014). In fact, the interannual variation of the frequency of occurrence of positive extreme SIC projection values (the number of days that the SIC projection time series exceeds one standard deviation from its mean) is significantly correlated with the interannual variation of SIC at -0.7 .

The projection time series (Fig. 3a) shows that days with large and positive downward IR radiation projections (the days when the downward IR radiation field resembles the downward IR radiation trend pattern) are often followed by positive SIC projections (the days when the SIC resembles the SIC trend pattern). This temporal relationship can be seen succinctly with lag correlations (Fig. 3b). Moreover, the upward trends of both time series indicate that trendlike daily anomalies of downward IR radiation and SIC have become more prominent over time (Fig. 3a). The effective emitters of downward IR radiation are cloud liquid water and cloud frozen water (Walsh and Chapman 1998; Intrieri et al. 2002; Stramler et al. 2011; Engström et al. 2014), and the moisture source for Arctic clouds can be either the Arctic Ocean or the midlatitude troposphere (Francis and Hunter 2006). Insight into these possibilities can be gained by examining the time evolution of evaporation, surface latent heat flux, and tropospheric water (vapor, liquid, and ice) flux convergence into the Arctic. For this purpose, we constructed lag composites of the various projection time series where the lag-0 days are defined as the days when the SIC projection values cross the $1 \sigma$ threshold.

The results, shown in Fig. 4, indicate that the downward IR radiation fluctuations are preceded by the horizontal flux of water (moisture, liquid, and ice) into the Arctic domain and not by the evaporation from the Arctic Ocean surface. Figure 4 reveals that the following sequence of events occurs: First, an anomalously large amount of tropospheric water converges [vertically integrated total column water convergence (VIWFC)] into the Arctic. Figures 5a,b show that this influx occurs through anomalous southerlies over the Greenland and Norwegian Seas. This composite water flux pattern closely resembles the trend pattern of the horizontal water fluxes (not shown). At the same time, as inferred by the direction of the vectors in Figs. 5a,b, there is warm air advection from midlatitudes into the Arctic, where an increase in the 1000-400-hPa mean temperature [tropospheric mean temperature (TMP)] is observed (Figs. 4, 5g-i). Over the region where water converges and warm advection occurs, evaporation is suppressed, while vertically integrated total column water (VIW) is increasing (Figs. 5a,b,d,e,g,h). Figure 4 shows that the atmospheric water flux convergence and warm air advection are followed shortly 
a) VIWFC (-5 lag days)

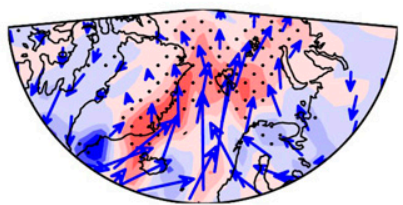

b) VIWFC (0 lag days)

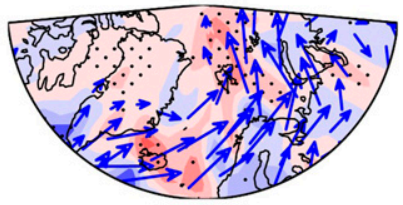

c) VIWFC (+5 lag days)

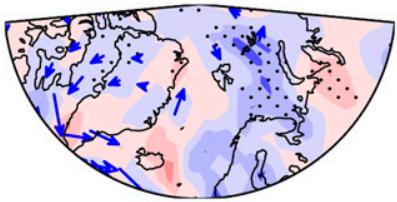

$2 \times 10^{7}$

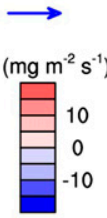

e) Evaporation (0 lag days)
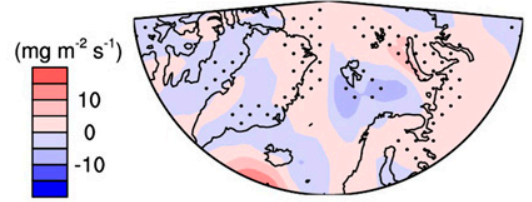

f) Evaporation (+5 lag days)

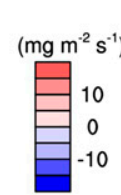

d) Evaporation (-5 lag days)
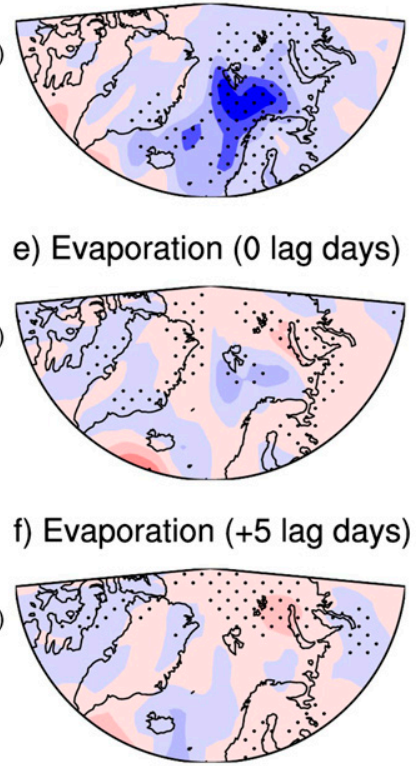

g) VIW \& TMP (-5 lag days)
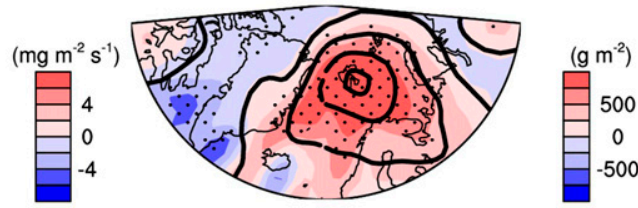

h) VIW \& TMP (0 lag days)
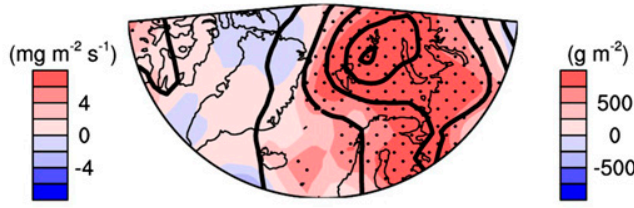

i) VIW \& TMP (+5 lag days)
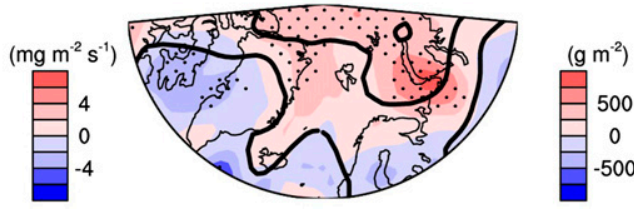

FIG. 5. Lag-day composites of (a)-(c) VIWFC, (d)-(f) evaporation, and (g)-(i) VIW content (color shading) and 1000-400-hPa TMP (thick black contours). Thick black contours are drawn in the region where TMP is positive. Dots and vectors indicate statistical significance at the $90 \%$ confidence level, evaluated with a Monte Carlo method where the composite values were compared against 10000 randomly selected samples.

afterward by an increase in downward IR radiation, with the anomalous VIW pattern resembling the downward IR radiation trend (cf. the right column in Fig. 5 with Fig. 2l). After a few days, the SIC begins to decline (recall that positive SIC projections correspond to a reduction in the SIC), while SST increases (Figs. 1, 2j). This is followed by increases in both the evaporation (Fig. 5f) and the surface (latent plus sensible) heat fluxes (not shown for latent plus sensible heat fluxes but their pattern coincides with that for evaporation) (also see Fig. 4), which mostly occur over the region where the SIC decreases (Fig. 1).

The lead-lag relationships in Fig. 4 along with the evaporation, VIWFC, and VIW in Fig. 5 indicate that the VIW and downward IR radiation increases precede the enhanced evaporation. This result indicates that the cloud water and moisture associated with the downward IR radiation originates from outside of the Arctic, not from the Arctic Ocean surface.

Our finding also indicates that on this short time scale, SST responds to downward IR radiation anomalies. However, since the ocean circulation has a much longer time scale, its full impact on sea ice cannot be evaluated using the approach used here. It may be that multidecadal variations of the ocean circulation also contribute to the SIC decline (Day et al. 2012), with this oceanic influence accounting for the majority of the SIC decline unexplained by downward IR radiation. In fact, the enhanced inflow of warm Atlantic water is found to reduce sea ice thickness via sea ice melting from its bottom surface (Spielhagen et al. 2011), and the resulting thinning of sea ice can make the SIC more susceptible to atmospheric forcing. Further investigation is necessary to assess the effect of this multidecadal oceanic heating on sea ice.

\section{Conclusions}

Our results suggest much of the recent decline in winter SIC across Baffin Bay and the Barents-Kara Seas can be attributed to the intensification of downward IR radiation over the winters of 1979-2011. This increase in downward IR radiation is caused by an influx of tropospheric water and heat from midlatitudes. Anomalously positive evaporation from the Arctic Ocean surface occurs with the SIC decline, but it lags the downward IR radiation by $6-10$ days and the SIC decline by $1-5$ days. Surface heat flux anomalies behave similar to the evaporation. Moreover, the effect of the autumn SIC decline is weaker than that by the downward IR radiation. All of these findings are at odds with the view that a warm season ice-albedo feedback process, through heat storage in the Arctic Ocean, is the main driver for the winter SIC decline. Instead, our result is consistent with previous studies that attribute the recent Arctic warming to large-scale circulation changes (Graversen 2006; Lee et al. 2011; Yoo et al. 2011; Ding et al. 2014; Lee 2014). This suggests that an accurate simulation of the large-scale circulation may hold 
the key to improving model projections of future sea ice decline.

Acknowledgments. This study was funded by Seoul National University, South Korea.

\section{REFERENCES}

Ballinger, T. J., and S. C. Sheridan, 2014: Associations between circulation pattern frequencies and sea ice minima in the western Arctic. Int. J. Climatol., 34, 1385-1394, doi:10.1002/joc.3767.

Cavalieri, D. J., C. L. Parkinson, P. Gloersen, and H. Zwally, 1996: Sea ice concentrations from Nimbus-7 SMMR and DMSP SSM/I-SSMIS passive microwave data (updated yearly). NASA DAAC at the National Snow and Ice Data Center. Subset used: December 1979 to February $2012,60^{\circ} \mathrm{N}$ to $90^{\circ} \mathrm{N}$ and $90^{\circ} \mathrm{W}$ to $90^{\circ} \mathrm{E}$, accessed 15 Oct 2013, doi:10.5067/ 8GQ8LZQVL0VL.

Comiso, J. C., 2006: Abrupt decline in the Arctic winter sea ice cover. Geophys. Res. Lett., 33, L18504, doi:10.1029/ 2006GL027341.

— C. L. Parkinson, R. Gersten, and L. Stock, 2008: Accelerated decline in the Arctic sea ice cover. Geophys. Res. Lett., 35, L01703, doi:10.1029/2007GL031972.

Day, J. J., J. C. Hargreaves, J. D. Annan, and A. Abe-Ouchi, 2012: Sources of multi-decadal variability in Arctic sea ice extent. Environ. Res. Lett., 7, 034011, doi:10.1088/1748-9326/7/3/034011.

Dee, D. P., and Coauthors, 2011: The ERA-Interim reanalysis: Configuration and performance of the data assimilation system. Quart. J. Roy. Meteor. Soc., 137, 553-597, doi:10.1002/qj.828.

Ding, Q., J. M. Wallace, D. S. Battisti, E. J. Steig, A. J. E. Gallant, H.-J. Kim, and L. Geng, 2014: Tropical forcing of the recent rapid Arctic warming in northeastern Canada and Greenland Nature, 509, 209-212, doi:10.1038/nature13260.

Engström, A., J. Karlsson, and G. Svensson, 2014: The importance of representing mixed-phase clouds for simulating distinctive atmospheric states in the Arctic. J. Climate, 27, 265-272, doi:10.1175/JCLI-D-13-00271.1.

Feldstein, S. B., 2002: Fundamental mechanisms of the growth and decay of the PNA teleconnection pattern. Quart. J. Roy. Meteor. Soc., 128, 775-796, doi:10.1256/0035900021643683.

Fowler, C., W. Emery, and M. Tschudi, 2013: Polar Pathfinder daily $25 \mathrm{~km}$ EASE-grid sea ice motion vectors, version 2. National Snow and Ice Data Center. Subset used: December 1979 to February $2012,60^{\circ} \mathrm{N}$ to $90^{\circ} \mathrm{N}$ and entire longitude, accessed 5 Aug 2014, doi:10.5067/LHAKY495NL2T.

Francis, J. A., and E. Hunter, 2006: New insight into the disappearing Arctic sea ice. Eos, Trans. Amer. Geophys. Union, 87, 509-511, doi:10.1029/2006EO460001.

—, and - 2007: Drivers of declining sea ice in the Arctic winter: A tale of two seas. Geophys. Res. Lett., 34, L17503, doi:10.1029/2007GL030995.

— _ - J. R. Key, and X. Wang, 2005: Clues to variability in Arctic minimum sea ice extent. Geophys. Res. Lett., 32, L21501, doi:10.1029/2005GL024376.

Graversen, R. G., 2006: Do changes in the midlatitude circulation have any impact on the Arctic surface air temperature trend? J. Climate, 19, 5422-5438, doi:10.1175/JCLI3906.1.

Intrieri, J. M., C. W. Fairall, M. D. Shupe, P. O. G. Persson, E. L. Andreas, P. S. Guest, and R. E. Moritz, 2002: An annual cycle of Arctic surface cloud forcing at SHEBA. J. Geophys. Res., 107, 8039, doi:10.1029/2000JC000439.
Kwok, R., G. F. Cunningham, M. Wensnahan, I. Rigor, H. J. Zwally, and D. Yi, 2009: Thinning and volume loss of the Arctic Ocean sea ice cover: 2003-2008. J. Geophys. Res., 114, C07005, doi:10.1029/2009JC005312.

Lee, S., 2014: A theory for polar amplification from a general circulation perspective. Asia-Pac. J. Atmos. Sci., 50, 31-43, doi:10.1007/s13143-014-0024-7.

_ , and S. B. Feldstein, 2013: Detecting ozone- and greenhouse gas-driven wind trends with observational data. Science, 339, 563-567, doi:10.1126/science.1225154.

— T. T. Ging, N. Johnson, S. B. Feldstein, and D. Pollard, 2011: On the possible link between tropical convection and the Northern Hemisphere Arctic surface air temperature change between 1958 and 2001. J. Climate, 24, 4350-4367, doi:10.1175/2011JCLI4003.1.

Lindsay, R. W., and J. Zhang, 2005: The thinning of Arctic sea ice, 1988-2003: Have we passed a tipping point? J. Climate, 18, 4879-4894, doi:10.1175/JCLI3587.1.

Rigor, I. G., J. M. Wallace, and R. L. Colony, 2002: Response of sea ice to the Arctic Oscillation. J. Climate, 15, 2648-2663, doi:10.1175/ 1520-0442(2002)015<2648:ROSITT >2.0.CO;2.

Schonher, T., and S. E. Nicholson, 1989: The relationship between California rainfall and ENSO events. J. Climate, 2, 1258-1269, doi:10.1175/1520-0442(1989)002<1258:TRBCRA > 2.0.CO;2.

Serreze, M. C., M. M. Holland, and J. Stroeve, 2007: Perspectives on the Arctic's shrinking sea-ice cover. Science, 315, 15331536, doi:10.1126/science.1139426.

Shimada, K., T. Kamoshida, M. Itoh, S. Nishino, E. Carmack, F. McLaughlin, S. Zimmermann, and A. Proshutinsky, 2006: Pacific Ocean inflow: Influence on catastrophic reduction of sea ice cover in the Arctic Ocean. Geophys. Res. Lett., 33, L08605, doi:10.1029/2005GL025624.

Simmonds, I., 2015: Comparing and contrasting the behaviour of Arctic and Antarctic sea ice over the 35 year period 19792013. Ann. Glaciol., 56, 18-28, doi:10.3189/2015AoG69A909.

Spielhagen, R. F., and Coauthors, 2011: Enhanced modern heat transfer to the Arctic by warm Atlantic water. Science, 331, 450-453, doi:10.1126/science.1197397.

Stramler, K., A. D. Del Genio, and W. B. Rossow, 2011: Synoptically driven Arctic winter states. J. Climate, 24, 1747-1762, doi:10.1175/2010JCLI3817.1.

Stroeve, J. C., V. Kattsov, A. Barrett, M. Serreze, T. Pavlova, M. Holland, and W. N. Meier, 2012a: Trends in Arctic sea ice extent from CMIP5, CMIP3 and observations. Geophys. Res. Lett., 39, L16502, doi:10.1029/2012GL052676.

_ M. C. Serreze, M. M. Holland, J. E. Kay, J. Malanik, and A. P. Barrett, 2012b: The Arctic's rapidly shrinking sea ice cover: A research synthesis. Climatic Change, 110,1005-1027, doi:10.1007/ s10584-011-0101-1.

Walsh, J. E., and W. L. Chapman, 1998: Arctic cloud-radiationtemperature associations in observational data and atmospheric reanalyses. J. Climate, 11, 3030-3045, doi:10.1175/ 1520-0442(1998)011<3030:ACRTAI>2.0.CO;2.

Wang, M., and J. E. Overland, 2009: A sea ice free summer Arctic within 30 years? Geophys. Res. Lett., 36, L07502, doi:10.1029/ 2009GL037820.

, and - 2012: A sea ice free summer Arctic within 30 years: An update from CMIP5 models. Geophys. Res. Lett., 39, L18501, doi:10.1029/2012GL052868.

Yoo, C., S. Feldstein, and S. Lee, 2011: The impact of the MaddenJulian Oscillation trend on the Arctic amplification of surface air temperature during the 1979-2008 boreal winter. Geophys. Res. Lett., 38, L24804, doi:10.1029/2011GL049881. 